\title{
Hydrological Models and Artificial Neural Networks (ANNs) to Simulate Streamflow in a Tropical Catchment of Sri Lanka
}

\author{
Miyuru B. Gunathilake ${ }^{1},{ }^{1,2}$ Chamaka Karunanayake, ${ }^{1}$ Anura S. Gunathilake, ${ }^{3}$ \\ Niranga Marasingha, ${ }^{2,3}$ Jayanga T. Samarasinghe, ${ }^{4}$ Isuru M. Bandara, ${ }^{3}$ \\ and Upaka Rathnayake $\mathbb{D}^{1}$ \\ ${ }^{1}$ Department of Civil Engineering, Faculty of Engineering, Sri Lanka Institute of Information Technology, New Kandy Road, \\ Malabe, Sri Lanka \\ ${ }^{2}$ Central Engineering Services (Pvt) Limited, Bauddhaloka Mawatha, Colombo 7, Sri Lanka \\ ${ }^{3}$ Central Engineering Consultancy Bureau, Bauddahloka Mawatha, Colombo 7, Sri Lanka \\ ${ }^{4}$ Faculty of Engineering, Sri Lanka Technological Campus, Padukka, Sri Lanka
}

Correspondence should be addressed to Miyuru B. Gunathilake; miyurubandaragunathilake@gmail.com

Received 16 December 2020; Revised 28 April 2021; Accepted 22 May 2021; Published 28 May 2021

Academic Editor: Jun He

Copyright (C) 2021 Miyuru B. Gunathilake et al. This is an open access article distributed under the Creative Commons Attribution License, which permits unrestricted use, distribution, and reproduction in any medium, provided the original work is properly cited.

\begin{abstract}
Accurate streamflow estimations are essential for planning and decision-making of many development activities related to water resources. Hydrological modelling is a frequently adopted and a matured technique to simulate streamflow compared to the data driven models such as artificial neural networks (ANNs). In addition, usage of ANNs is minimum to simulate streamflow in the context of Sri Lanka. Therefore, this study presents an intercomparison between streamflow estimations from conventional hydrological modelling and ANN analysis for Seethawaka River Basin located in the upstream part of the Kelani River Basin, Sri Lanka. The hydrological model was developed using the Hydrologic Engineering Centre-Hydrologic Modelling System (HECHMS), while the data-driven ANN model was developed in MATLAB. The rainfall and streamflows' data for 2003-2010 period have been used. The simulations by HEC-HMS were performed by four types of input rainfall data configurations, including observed rainfall data sets and three satellite-based precipitation products (SbPPs), namely, PERSIANN, PERSIANN-CCS, and PERSIANN-CDR. The ANN model was trained using three well-known training algorithms, namely, Levenberg-Marquadt (LM), Bayesian regularization (BR), and scaled conjugate gradient (SCG). Results revealed that the simulated hydrological model based on observed rainfall outperformed those of based on remotely sensed SbPPs. BR algorithm-based ANN algorithm was found to be superior among the data-driven models in the context of ANN model simulations. However, none of the above developed models were able to capture several peak discharges recorded in the Seethawaka River. The results of this study indicate that ANN models can be used to simulate streamflow to an acceptable level, despite presence of intensive spatial and temporal data sets, which are often required for hydrologic software. Hence, the results of the current study provide valuable feedback for water resources' planners in the developing region which lack multiple data sets for hydrologic software.
\end{abstract}

\section{Introduction}

Streamflow is one of the responses of integrated atmospheric and topographic processes. Developing the flow hydrograph using observed streamflow measurements is an important task. Many methods (velocity-area methods, formed constriction methods, and noncontact measurement methods) are available to measure streamflow rates [1]. However, continuous streamflow measurements are not always available in developing nations, mainly due to associated costs for installment and maintenance of hydrological networks [2]. In addition, fine resolution spatial data sets including land use and soil data are not always available in these regions. Therefore, computational models to estimate 
streamflows are given a significant attention. However, accurate streamflow estimation is highly important for many stakeholders including water resources management, hydropower development, and agricultural management [3].

Among many other available computer models used for simulating rainfall-runoff processes, the Soil and Water Assessment Tool [4], the Hydrologic Engineering CentreHydrologic Modelling System (HEC-HMS) [5], the Variable Infiltration Capacity Model [6], the HBV-light model [7], and the J2000 model [8] are frequently used by hydrological modellers around the world [9-11]. However, time-series hydrological models inherit uncertainties in streamflow estimations due to unavailability of long-term data including meteorological and streamflow data [12].

Importantly, due to lack of dense rain gauge networks, especially in the developing regions, researchers have tended to use remotely sensed satellite-based precipitation products (SbPPs). These SbPPs are attractive since they are freely available and provide data with temporal consistency in fine temporal and spatial resolutions appealing in hydrological applications. Hence, SbPPs can address many shortcomings faced when measuring precipitation through ground-based rain gauges. However, the accuracy of SbPPs should be tested prior to its applications $[13,14]$.

At the same time, advancements of science and computer technology have aided the development of soft computing tools, such as artificial neural networks (ANNs), the adaptive neuro-fuzzy inference system, and support vector system [15] to simulate the streamflows using the available data. Among these soft computing tools, it is witnessed that there is a growing demand and use in ANNs for multiple applications, including streamflow estimations [3] and future hydropower generation estimates [16], in understanding relationships between future climate and crop yield $[17,18]$.

Although ANN approach has been adopted in streamflow forecasting in various parts of the world [19-21], this technique has not much given attention for the context of Sri Lanka other than [22-25].

Acknowledging the needs of examining the capability of ANNs for streamflow estimations in Sri Lankan catchments, the present study was carried out in the Seethawaka River Basin. The studied river is a major tributary of the Kelani River Basin, Sri Lanka. The simulated streamflow from the HEC-HMS hydrological model and the ANN model was compared against observed streamflow records in this study. The results of this study will be valuable for the planning and management of water resources in the Seethawaka River Basin. The methodology adopted in this study can be replicated in other river basins, which is lacking in temporal and spatial data.

\section{Study Area}

The Seethawaka River Basin is a subbasin of the Kelani River Basin (Kelani River is one of the most important rivers in Sri Lanka in the wet zone of the country). It drains a catchment area of $223 \mathrm{~km}^{2}$ and is about $57 \mathrm{~km}$ long. The location map of Seethawaka River is given in Figure 1. It lies between

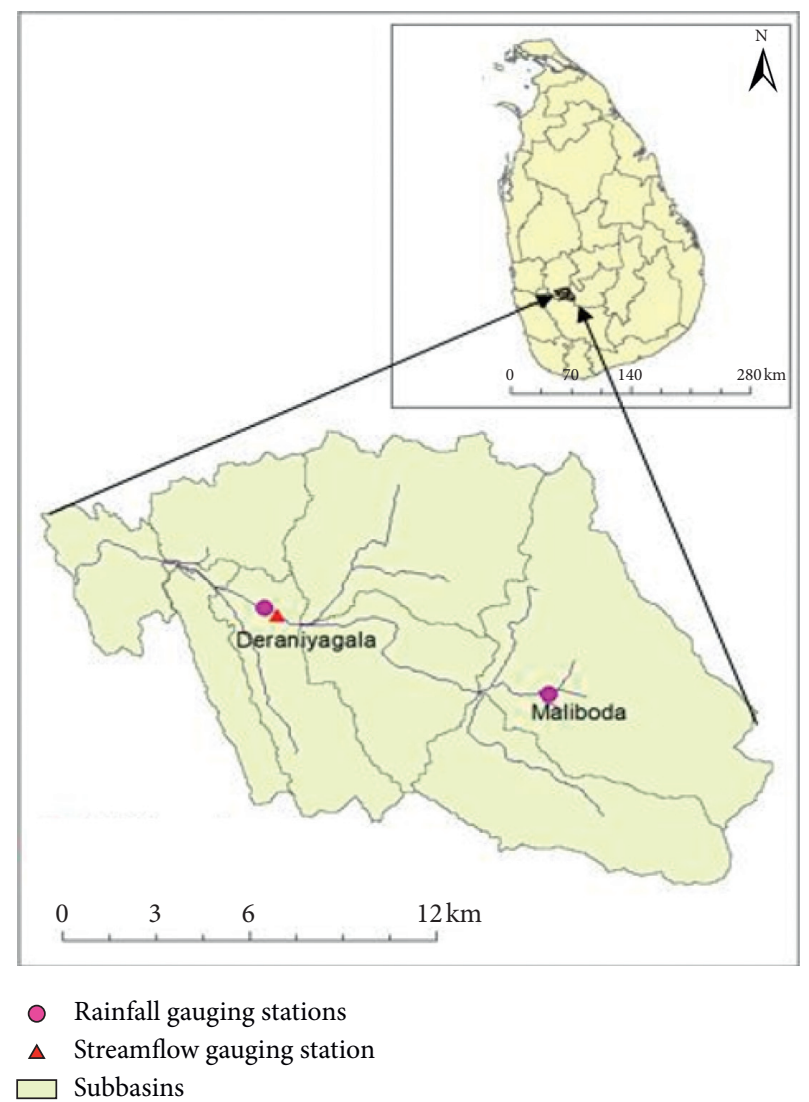

FIGURE 1: Location of rainfall and streamflow gauging stations in the Seethawaka River.

latitudes of $6^{\circ} 50^{\prime}$ and $7^{\circ} 00^{\prime} \mathrm{N}$ and longitudes of $80^{\circ} 17^{\prime}$ and $80^{\circ} 30^{\prime} \mathrm{E}$. The locations of available rainfall and streamflow gauging stations within the catchment are given in Figure 1. The main tributaries of the Seethawaka River are Magal and Panapura streams.

The upper part of Seethawaka catchment (Maliboda region) receives an average annual rainfall of $4000-5000 \mathrm{~mm}$ [26]. Moreover, the upper part is covered with dense forests and rubber plantation. The downstream catchment of the river comprises homestead gardens and tea and paddy cultivation at various ground levels (refer Figure 2(a) and 2(b)). The soil types of the catchment area are clay with a loamy nature, which has moderate infiltration rates [27].

The Seethawaka River has a steep channel slope (on average of $31 \mathrm{~m}$ drop for $1 \mathrm{~km}$ ), which is highly important for hydropower generation. Due to this reason the Ceylon Electricity Board is planning to fund for the construction of a hydropower plant along Seethawaka, which can produce $30 \mathrm{MW}$. At the same time, several mini-hydropower stations can be found along the Seethawaka River.

\section{Methodology}

3.1. Data for the Study. The daily rainfall data from 2003 to 2010 years at Maliboda and Deraniyagala rain gauging stations were purchased from the Department of Meteorology of Sri Lanka. The observed rainfall data since 2010 for 

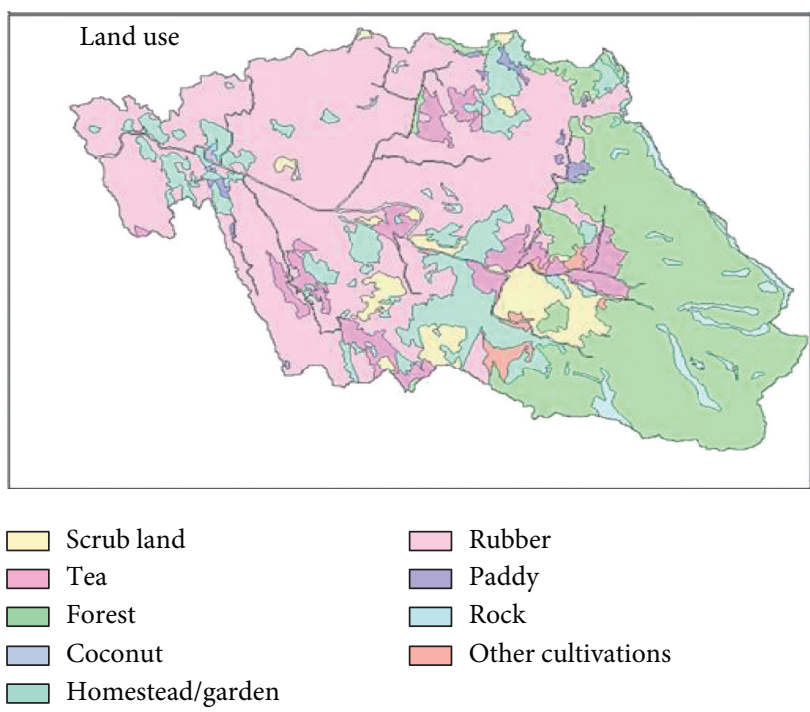

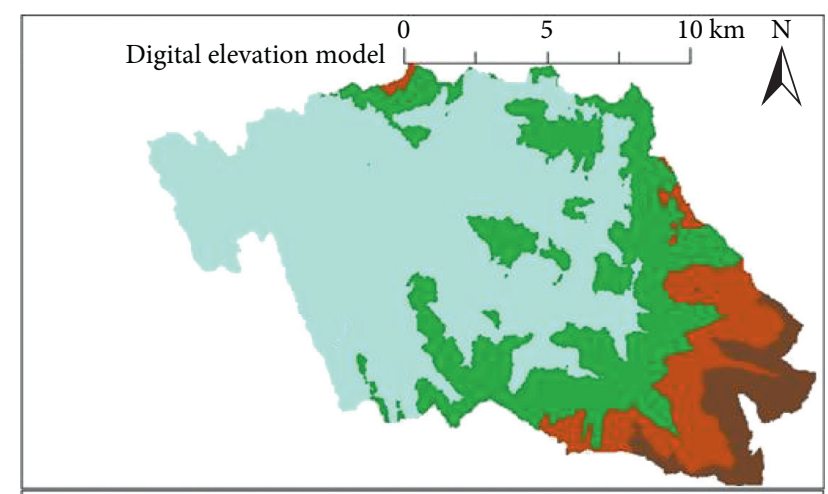

Elevation (m above m.s.l.)

$$
\begin{aligned}
& \square \quad 50-400 \\
& \square \quad 400-800 \\
& \square \quad 800-1200 \\
& \square \text { 1200-1800 } \\
& \square \quad 1800-1831
\end{aligned}
$$

(a)

(b)

Figure 2: Land use and topography of Seethawaka river. (a) Land use pattern. (b) Digital elevation model.

Maliboda rain gauging station are not comprehensive and they are with many gaps. Therefore, the study has to be limited to year 2010. In addition to that, daily streamflow data were obtained from the Irrigation Department of Sri Lanka. The Digital Elevation Model (DEM) of the Seethawaka River Basin was extracted from the Global Mapper available in https:/www.bluemarblegeo.com/products/ global-mapper.php. The DEM used for the model developed was available in $10 \mathrm{~m} \times 10 \mathrm{~m}$ resolution. The land use data and soil data were obtained from the Survey Department of Sri Lanka and Harmonized World Soil Database, respectively.

The precipitation data from Precipitation Estimates from Remotely Sensed Information using Artificial Neural Networks (PERSIANN), PERSIANN Cloud Classification System (PERSIANN-CCS), and PERSIANN-Climate Data Record (PERSIANN-CDR) were obtained for this study. PERSIANN data are available from the year 2000 with spatial and temporal resolutions of 0.25 and 1 hour, respectively. In addition, PERSIANN-CCS data are available from the year 2003 with spatial resolution and temporal resolutions of 0.04 and 1 hour, respectively. However, PERSIANN-CDR data sets are available from the year 1983, and therefore, they can be used for long-term monitoring of changes in climate. The spatial and temporal resolutions of these data sets are 0.25 and 1 day, respectively. Detailed information of the aforementioned SbPPs and extraction can be done from https:// chrsdata.eng.uci.edu/. The readers are encouraged to refer [28] for detailed information of PERSIANN family of products.

\subsection{Hydrological Modelling of Seethawaka Catchment.} The HEC-HMS model [29] has a wide range of applications in different parts of the world including evaluation of the impact of climate change on hydrology [30], incorporating low-impact development and best management practices in hydrological simulations [31], and assessing the impact of urbanization on flash floods [32]. Many researchers have used the HEC-HMS model for event-based and long-term simulations in the Sri Lankan context [33-37].

In this study, the basin model was developed by feeding the DEM into the Hydrologic Modelling System-Geospatial Hydrologic Modelling Extension in the Arc-Geographical Information Systems. The developed model was applied to simulate streamflow. A time step equal to a day was used. An initial warm-up period was provided to equilibrate between various water storages in the hydrological cycle. Rainfall data from 2003 onward were selected for this study due to the unavailability of CCS data before that. The hydrological model developed for this study was calibrated in between 2003 to 2006 ( 4 years) and validated in between 2007 to 2010 (4 years) by comparing with observed streamflow at the Deraniyagala streamflow gauging station operated by the Department of Irrigation of Sri Lanka.

The observed rainfall data were only used for this calibration. Previous studies including [38] have calibrated the Soil and Water Assessment Tool (SWAT) to simulate streamflow with observed rain gauge data, while multisatellite precipitation data sets were only used to drive the SWAT model without changing the calibrated parameters. These parameters were obtained through the model calibration carried out by inputs for meteorological forcing from ground observed rain gauges. Therefore, a similar technique was used in this study for the calibration. Precipitation losses, direct runoff transformation, baseflow, and routing were simulated by Soil and Moisture Accounting (SMA) model, Clark Unit Hydrograph, recession method, and Muskingum and lag methods, respectively. The same set of parameters used to calibrate the model with input of rain gauges was used to simulate the models which used input rainfall data from SbPPs. This calibration approach enables 
to evaluate the differences of SbPPs affecting the reliability of streamflow simulations.

Upstream catchment of Seethawaka comprises a dense forest cover. Therefore, canopy losses were also simulated in conjunction with the SMA model. The canopy cover values for specific land use classes were obtained from [39], whereas values of hydraulic conductivity in soils were obtained from [40]. These values are given in the Table 1 .

Flow routing was carried out by Muskingum and lag methods. It was observed that the upper reaches of Seethawaka River are steep; therefore, the lag method, which was recommended by Nandalal and Rathnayake, [36] was used. In addition, the manual calibration was performed in this study to satisfy the goodness fit criterion between observed and simulated streamflow values by maximizing Nash Sutcliffe Efficiency Coefficient (NSE). The parameters were adjusted based on the guidelines provided in [5].

In addition, De Silva et al. [33] have developed the HECHMS model to simulate streamflow of the Kelani River Basin (major river basin), which the Seethawaka River Basin (subbasin) is of. Moreover, in the same study, De Silva et al. [33] have reported that the sensitive parameters for streamflow when using Soil Moisture Accounting Method (SMA) are percentage imperviousness and tension storage. Hence, in the present study, the values of percentage imperviousness and tension storage were varied to satisfy the best-fit criterion between observed and simulated discharges.

Therefore, four hydrological models were simulated for Seethawaka catchment using observed rainfall, PERSIANN rainfall, PERSIANN-CCS rainfall, and PERSIANN-CDR rainfall values. These four simulated models were compared against observed streamflow. Statistical indicators including coefficient of determination $\left(R^{2}\right)$, Nash-Sutcliffe efficiency (NSE), and percentage error in volume (PEV) were used to evaluate the accuracy of model simulations.

3.3. Artificial Neural Network Modelling of Seethawaka Streamflow. As it was stated earlier, ANNs can be used to develop nonlinear relationships among variables. Therefore, the following relationship was formulated using ANN (equation (1)), where the streamflow of Seethawaka River Basin is a nonlinear function $(\phi)$ of the receiving rainfall:

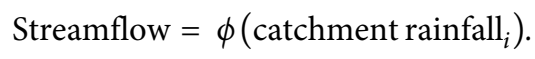

The above relationship was modelled in the mathematical computing package, MATLAB. The neural network was modelled with one hidden layer in addition to the input and output layers. The daily rainfall data for Maliboda and Deraniyagala were fed to the system as inputs. The neural network was trained using the known Deraniyagala streamflow data. Seventy percent of the time-series data were used to the training process, while $15 \%$ of each was used to validating and testing processes. Three commonly used training algorithms, including Levenberg-Marquardt (LM), Bayesian regularization (BR), and scaled conjugate gradient (SCG), were incorporated in the training process of the developed ANNs. Among the three training algorithms, the
TABLE 1: Calibrated parameters in the SMA method.

\begin{tabular}{lc}
\hline Parameters & Value \\
\hline Soil $(\%)$ & 70 \\
Groundwater 1 (\%) & 45 \\
Groundwater 2 (\%) & 82 \\
Max infiltration (mm/hr) & 3.5 \\
Imperviousness (\%) & 25 \\
Soil storage $(\mathrm{mm})$ & 125 \\
Tension storage $(\mathrm{mm})$ & 75 \\
Soil percolation $(\mathrm{mm} / h)$ & 0.75 \\
Groundwater 1 storage $(\mathrm{mm})$ & 100 \\
Groundwater 1 percolation $(\mathrm{mm} / h)$ & 1 \\
Groundwater 1 coefficient $(h)$ & 100 \\
Groundwater 2 storage $(\mathrm{mm})$ & 150 \\
Groundwater 2 percolation $(\mathrm{mm} / \mathrm{h})$ & 1 \\
Groundwater 2 coefficient $(h)$ & 1 \\
\hline
\end{tabular}

best was selected based on the coefficient of determination $\left(R^{2}\right)$ and mean squared error (MSE). Previous studies, including [41-43] and [44], have used R2 and MSE to evaluate the performance of training algorithms.

3.4. Overall Methodology as a Summary. The hydrological model was developed using the Hydrologic Engineering Centre-Hydrologic Modelling System (HEC-HMS), while the data-driven ANN model was developed in MATLAB. The rainfall and corresponding streamflow data records between the 2003 to 2010 period were used in the present study. The simulations by HEC-HMS were performed by four types of input rainfall data configurations, including observed rainfall data sets and three satellite-based precipitation products (SbPPs), namely, PERSIANN, PERSIANNCCS, and PERSIANN-CDR. Moreover, the ANN model was trained using three well-known training algorithms, namely, Levenberg-Marquadt (LM), Bayesian regularization (BR), and scaled conjugate gradient (SCG).

\section{Results and Discussion}

4.1. Results of Streamflow Estimations from the Hydrological Model. Figure 3 demonstrates the comparison between the hydrological modelled streamflow discharges and observed streamflow discharges. The rainfall plotted in the secondary $y$-axis is average rainfall recorded from different precipitation products. Figure 3(a) presents the hydrograph obtained through forcing the model by observed rainfall, whereas Figures 3(b)-3(d) present hydrographs obtained from the model simulated from precipitation input from PERSIANN, PERSIANN-CCS, and PERSIANN-CDR, respectively. It can be clearly seen that the simulated streamflow discharges were underpredicted compared to the observed streamflow discharges. However, the eyeball analysis shows that the hydrograph presented in Figure 3(a) has the best simulated streamflow discharges. Nevertheless, all four hydrographs follow the patterns of observed streamflow hydrograph.

Table 2 presents the model performance of the hydrological models simulated by different precipitation products. 


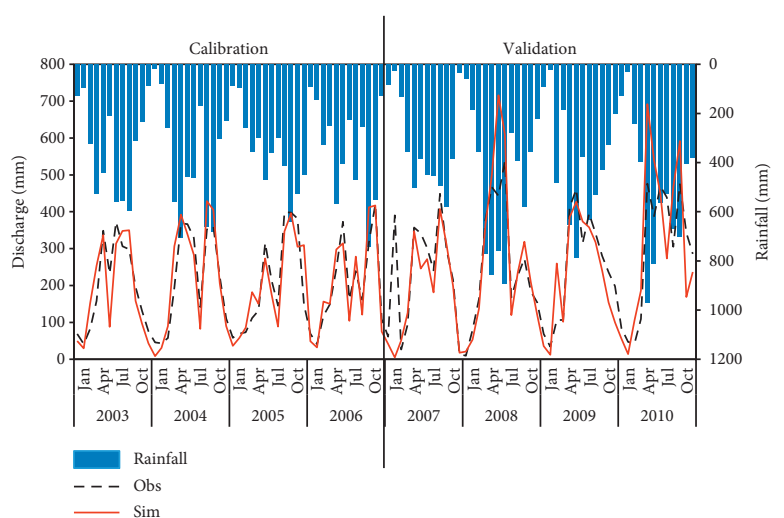

(a)

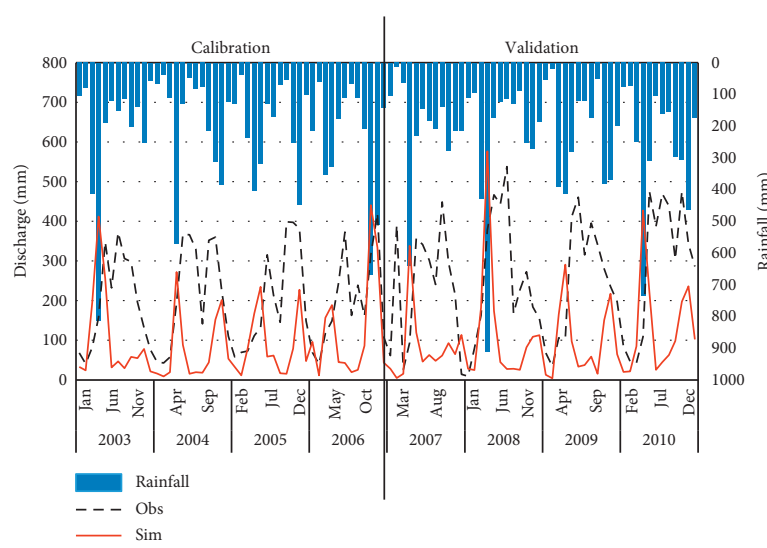

(c)

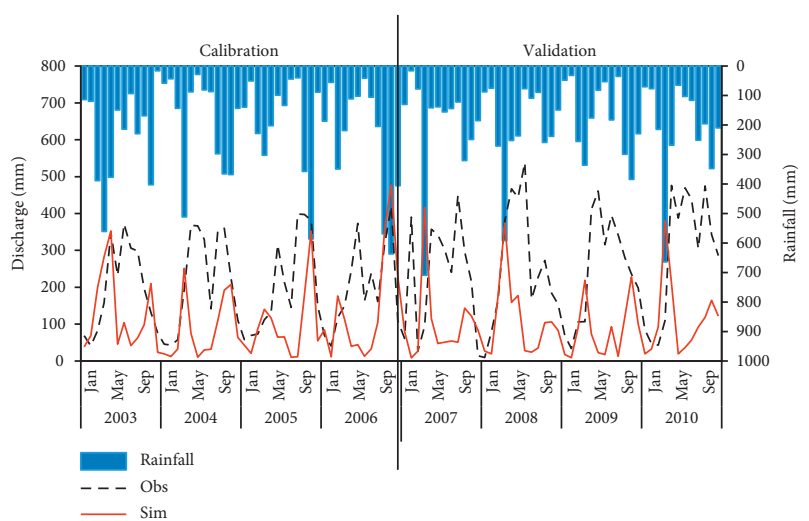

(b)

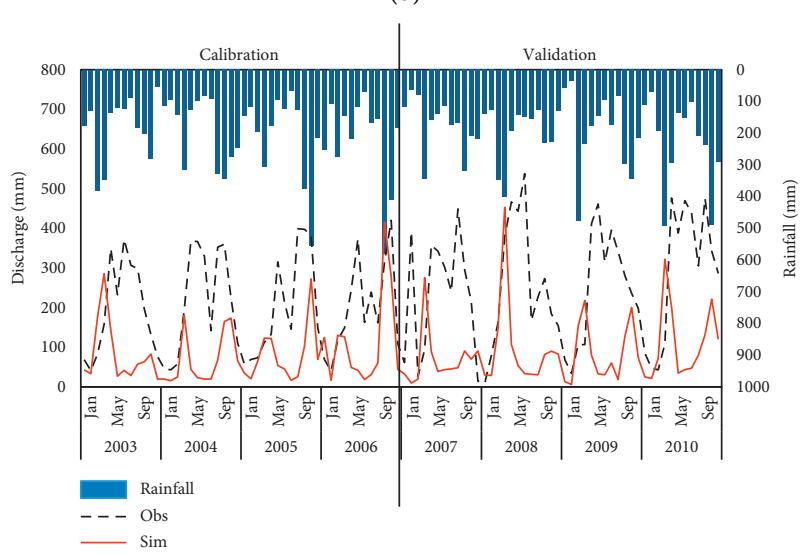

(d)

FIGURE 3: Simulated streamflow from hydrological modelling with inputs from different precipitation products: (a) for observed rainfall, (b) for PERSIANN, (c) for PERSIANN-CCS, and (d) for PERSIANN-CDR.

TABle 2: Hydrological model performance under different precipitation data sets.

\begin{tabular}{lccccccc}
\hline \multirow{2}{*}{$\begin{array}{l}\text { Precipitation } \\
\text { products }\end{array}$} & \multicolumn{3}{c}{ Calibration } & \multicolumn{3}{c}{ Validation } \\
& $R^{2}$ & NSE & $\begin{array}{c}\text { PEV } \\
(\%)\end{array}$ & $R^{2}$ & NSE & $\begin{array}{c}\text { PEV } \\
(\%)\end{array}$ \\
\hline Observed rainfall & 0.81 & 0.79 & 0.56 & 0.71 & 0.57 & 0.01 \\
PERSIANN & 0.11 & -0.76 & 45 & 0.01 & -1.4 & 60 \\
PERSIANN-CCS & 0.05 & -1.14 & 52 & 0.01 & -1.45 & 58 \\
PERSIANN-CDR & 0.07 & -1.06 & 57 & 0.01 & -1.45 & 65 \\
\hline
\end{tabular}

NSE denotes Nash-Sutcliffe efficiency and PEV denotes percentage error in volume.

The calculated coefficient of determination $\left(R^{2}\right)$ values clearly show that the model based on observed rainfall gives better simulation results $\left(R^{2}\right.$ is closer to 1$)$. Three SbPPs were shown the least possibility in proving the accurate simulated results. In addition, the NSE values are negative and the PEV values are higher for these three cases. However, the model based on the observed rainfall data presents an acceptable R2 with positive NSE values along with lower PEVs $(<1)$ [45]. Therefore, it can be clearly seen that the hydrologic model based on observed rainfall outperform the models forced by SbPPs.

The precipitation is the only difference input to the hydrological model. Hence, disparities in precipitation are the major reasons for mismatches between observed and simulated flows. Precipitation from satellite rainfall data sets significantly underestimated the observed rainfall, which can lead to inaccurate performance of streamflow simulations. Such observation has been witnessed in previous studies from the PERSIANN precipitation data, which was used in watersheds of South Korea by [38] and Sri Lanka by [46].

4.2. Streamflow Estimations from ANN Models. Estimated streamflow against the observed rainfall from the ANN model under LM, BR, and SCG training algorithms are plotted in Figure 4. It can be clearly seen that coefficient of determination values are not the best. However, among three tested training algorithms, BR algorithm has the best $R^{2}$. In addition, BR algorithm-based ANN model has the lowest MSE (154) compared to others. Therefore, BR algorithm-based ANN can be selected as an acceptable model for the flow simulation of the Seethawaka River.

4.3. Comparison of Streamflow Simulations. Figure $5 \mathrm{dem}-$ onstrates the comparison of streamflow in Seethawaka River for the period between 2003 and 2010. The blue line represents the observed streamflow (Observed SF) over the 8 year period, while the dashed lines represent hydrologic 


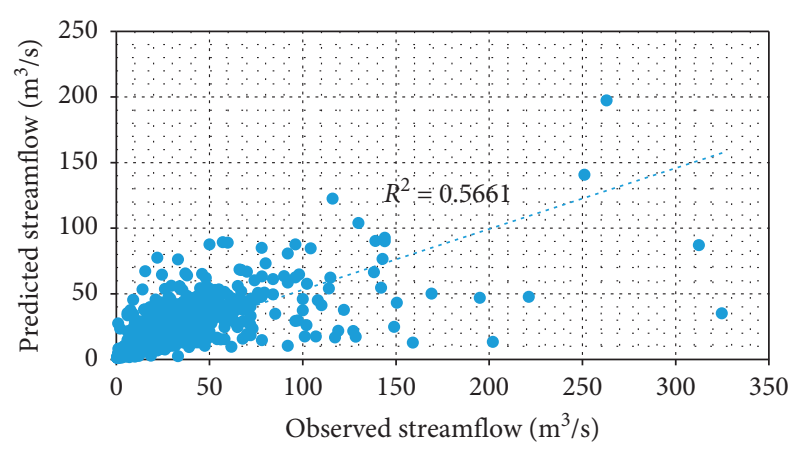

(a)

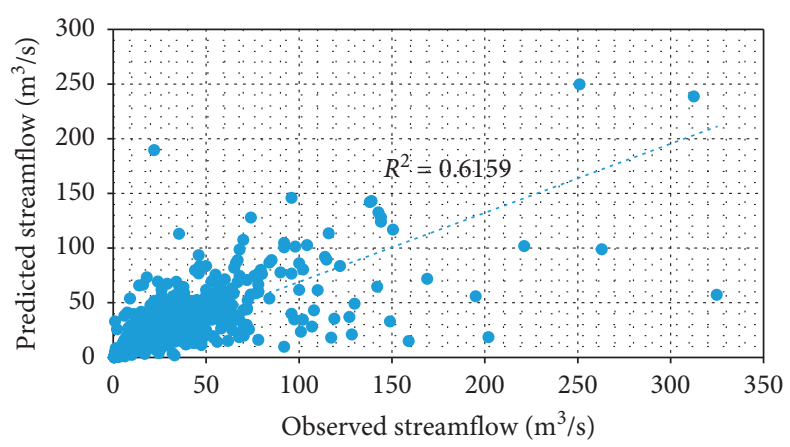

(b)

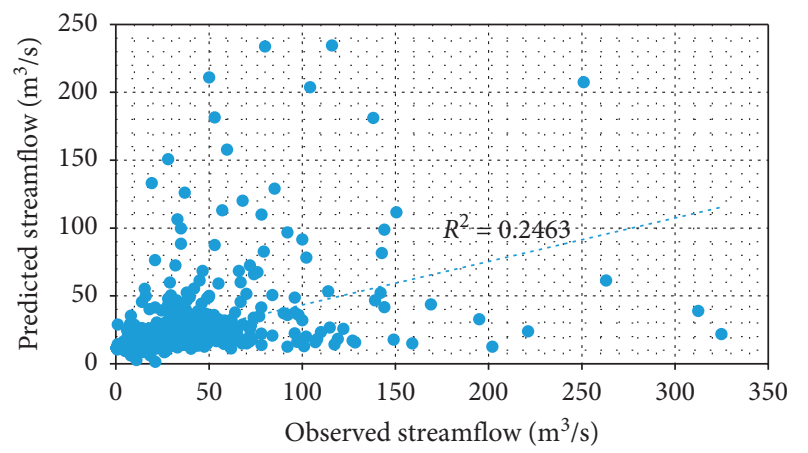

(c)

FIGURE 4: ANN Predicted and observed streamflow: (a) for LM algorithm, (b) for BR algorithm, and (c) for SCG algorithm.

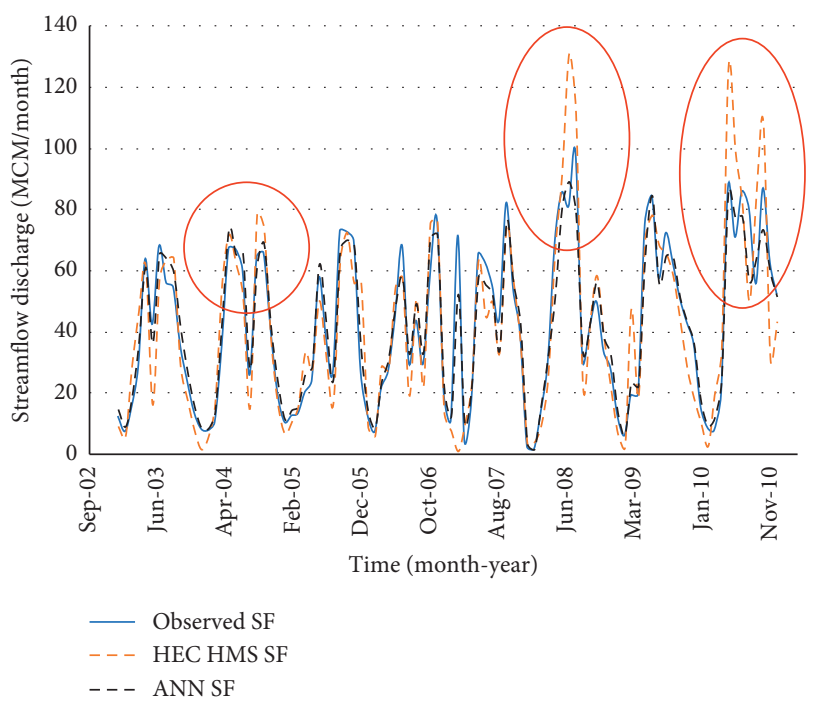

FIGURE 5: Streamflow comparison of Seethawaka River.

models simulated (HEC-HMS SF) and ANN simulated (ANN SF) streamflows. It can be clearly seen that the discharge patterns follow a similar pattern consistent with observed streamflow. However, the HEC-HMS SF and ANN SF are unable to capture the peak discharge rates (see the red colour circles). Nevertheless, this observation is notable in HEC-HMS SF, while ANN SF is somewhat acceptable. Therefore, in a simulation process, ANN-induced streamflow can be potentially used.
4.4. Discussion on the Related Previous Work. Mixed school of results are found from the previous analyses. Rauf and Ghumman [47] concluded that the HEC-HMS hydrological model performs better than the data-driven ANN model in simulating streamflows. However, Young and Liu [48] showed that the hybrid model, which includes both HECHMS and ANN produces more accurate results. Loyeh and Jamnani [49] concluded that the ANN model is better than the HEC-HMS model in simulating streamflow for catchment in Iran.

In addition, Tramblay et al. [50] have conducted a comparison of the hydrological model for Morocco using observed rainfall and obtained precipitation products. However, they have not used ANN technique for the comparison. Instead, they have compared the streamflows generated by GR4J model, which was developed by Perrin et al. [51]. However, Tramblay et al. [50] have concluded that TRMM product project closest to the observed precipitation, thus, reproduces monthly dynamics of streamflows in the catchment.

Similar analysis was carried out many researchers $[52,53]$; however, most of them have not incorporated the ANN work to their analyses. In addition, some others have focused on the ANN work to showcase the streamflows with respect to the satellite-based precipitation products. Nevertheless, a holistic approach, which incorporates observed rainfall data and satellite precipitation products to both hydrological modelling and artificial neural network modelling, is limited in the literature. Therefore, the research presented here is interesting. However, it is difficult to state a 
better model one over the other in general; therefore, case specific analyses are recommended.

\section{Conclusions}

By comparison of streamflow of Seethawaka River Basin through hydrologic modelling HEC-HMS and data-driven techniques, ANN was carried out in this study. Hydrological modelling results revealed that the simulations with input from observed rainfall produced the best streamflow estimates compared to the streamflows generated from SbPPs. In addition, results from the ANN analysis reveal that the BR training algorithm outperformed in simulating the streamflows as compared to the other tested training algorithms. It was noted that the results from hydrologic modelling and ANN against observed streamflow showed that none of the streamflows can make simulated accurately, especially in capturing peak flows. However, streamflows based on ANN analysis can be accepted for specific purposes with a certain error. Nevertheless, future research is needed in fine tuning the acceptability of the simulation results.

\section{Data Availability}

The climatic data and the analysis data are available from the corresponding author upon request.

\section{Disclosure}

The research was carried out in the Sri Lanka Institute of Information Technology environment.

\section{Conflicts of Interest}

The authors declare no conflicts of interest.

\section{Acknowledgments}

The authors of this paper are extremely thankful to the Department of Irrigation Sri Lanka and Department of Surveys for the provision of required data sets to carry out this study.

\section{References}

[1] P. Dobriyal, R. Badola, C. Tuboi, and S. Hussain, "A review of methods for monitoring streamflow for sustainable water resource management," Applied Water Science, vol. 7, no. 6, pp. 2617-2628, 2016.

[2] V. Lakshmi, J. Fayne, and J. Bolten, "A comparative study of available water in the major river basins of the world," Journal of Hydrology, vol. 567, pp. 510-532, 2018.

[3] P. Pradhan, T. Tingsanchali, and S. Shrestha, "Evaluation of soil and water assessment tool and artificial neural network models for hydrologic simulation in different climatic regions of Asia," Science of Total Environment, vol. 701, Article ID 134308, 2020

[4] J. G. Arnold, R. Srinivasan, R. S. Muttiah, and J. R. Williams, "Large area hydrologic modeling and assessment Part I: model development," Journal of the American Water Resources Association, vol. 34, no. 1, pp. 73-89, 1998.

[5] A. D. Feldman, Hydrologic Modeling System HEC-HMS: Technical Reference Manual, US Army Corps of Engineers, Hydrologic Engineering Center, Davis, California, United States, 2000.

[6] X. Liang, D. P. Lettenmaier, E. F. Wood, and S. J. Burges, “A simple hydrologically based model of land surface water and energy fluxes for general circulation models," Journal of Geophysical Research: Atmospheres, vol. 99, no. D7, pp. 14415-14428, 1994.

[7] J. Seibert, HBV Light, Version 2; User's Manual, Department of Physical Geography and Quaternary Geology, Stockholm University, Stockholm, Sweden, 2005.

[8] P. Krause, "Quantifying the impact of land use changes on the water balance of large catchments using the J2000 model," Physics and Chemistry of the Earth, vol. 27, no. 9, pp. 663-673, 2002.

[9] M. Adib, M. Rowshon, M. Mojid, and I. Habibu, "Projected streamflow in the kurau river basin of western Malaysia under future climate scenarios," Scientific Reports, vol. 10, no. 1, Article ID 8336, 2020.

[10] M. Azmat, M. Choi, T.-W. Kim, and U. W. Liaqat, "Hydrological modeling to simulate streamflow under changing climate in a scarcely gauged cryosphere catchment," Environmental Earth Sciences, vol. 75, no. 3, pp. 1-16, 2016.

[11] Z. Bao, J. Liu, J. Zhang et al., "Estimation of baseflow parameters of variable infiltration capacity model with soil and topography properties for predictions in ungauged basins," Hydrology and Earth System Sciences Discussions, vol. 8, no. 4, pp. 7017-7053, 2011.

[12] J. S. Alagha, A. M. Said, and Y. Mogheir, "Review-artificial intelligence based modelling of hydrological processes," in Proceedings of the 4th International Engineering Conference-Towards Engineering of 21st Century, pp. 1-13, Gaza, October 2012.

[13] A. Irvem and M. Ozbuldu, "Evaluation of satellite and reanalysis precipitation products using GIS for all basins in Turkey," Advances in Meteorology, vol. 2019, pp. 1-11, 2019.

[14] Q. Jiang, W. Li, J. Wen et al., "Evaluation of satellite-based products for extreme rainfall estimations in the eastern coastal areas of China," Journal of Integrative Environmental Sciences, vol. 16, no. 1, pp. 191-207, 2019.

[15] E. Olyaie, H. Banejad, K.-W. Chau, and A. M. Melesse, "A comparison of various artificial intelligence approaches performance for estimating suspended sediment load of river systems: a case study in United States," Environmental Monitoring and Assessment, vol. 187, no. 4, p. 189, 2015.

[16] B. Khaniya, C. Karunanayake, M. B. Gunathilake, and U. Rathnayake, "Projection of future hydropower generation in Samanalawewa power plant, Sri Lanka," Mathematical Problems in Engineering, vol. 2020, pp. 1-11, 2020.

[17] V. Amaratunga, L. Wickramasinghe, A. Perera, J. Jayasinghe, and U. Rathnayake, "Artificial neural network to estimate the paddy yield prediction using climatic data," Mathematical Problems in Engineering, vol. 2020, pp. 1-11, 2020.

[18] I. L. Wickramasinghe, J. M. J. W. Jayasinghe, and U. Rathnayake, "Relationships between climatic factors to the paddy yeild: a case study from North-Western province of Sri Lanka," in Proceedings of the international Research Conference on Smart Computing and Systems Engineering 2020, University of Kelaniya, Sri Lanka, September 2020.

[19] H. Dalkiliç and S. Hashimi, "Prediction of daily streamflow using artificial neural networks (ANNs), wavelet neural 
networks (WNNs), and adaptive neuro-fuzzy inference system (ANFIS) models," Water Supply, vol. 20, no. 4, pp. 1396-1408, 2020.

[20] Ö. Kişi, "Streamflow forecasting using different artificial neural network algorithms," Journal of Hydrologic Engineering, vol. 12, no. 5, pp. 532-539, 2007.

[21] A. D. Mehr, E. Kahya, A. Şahin, and M. Nazemosadat, "Successive-station monthly streamflow prediction using different artificial neural network algorithms," International Journal of Environmental Science and Technology, vol. 12, no. 7, pp. 2191-2200, 2014.

[22] N. Basnayake, D. Attygalle, L. Liyanage, and K. Nandalal, "Ensemble forecast for monthly reservoir inflow; a dynamic neural network approach," in Proceedings of the 4th International Conference on Operational Research and Statistics, pp. 84-90, World Academy of Science, Engineering and Technology, Singapore, January 2016.

[23] H. Hapuarachchi, L. Zhijia, and A. Flugel, "Application of models with different types of modelling methodologies for river flow forecasting," Weather Radar Information and Distributed Hydrological Modelling, vol. 282, pp. 218-226, 2003.

[24] P. Hunukumbura and S. Weerakoon, "Comparison of two hydrological model applications for stream flow predictions in the upper Kotmale basin," in Proceedings of the 8th Peradeniya University Research Sessions, p. 85, Sri Lanka, October 2003.

[25] U. Selventhiran, H. Premaratne, and D. Sonnadara, 'An Artificial Neural Network Model for River Flow Forecasting', 28th Proceedings of the Technical Sessions, pp. 15-21, Kelaniya: Institute of Physics, Sri Lanka, 2012.

[26] W. G. M. Bastiaanssen and L. Chandrapala, "Water balance variability across Sri Lanka for assessing agricultural and environmental water use," Agricultural Water Management, vol. 58, no. 2, pp. 171-192, 2003.

[27] FAO and IIASA, Harmonized World Soil Database (Internet), http://webarchive.iiasa.ac.at/Research/LUC/External-Worldsoil-database/HTML/, 2012.

[28] P. Nguyen, M. Ombadi, S. Sorooshian et al., "The PERSIANN family of global satellite precipitation data: a review and evaluation of products," Hydrology and Earth System Sciences, vol. 22, no. 11, pp. 5801-5816, 2018.

[29] M. J. Fleming, Hydrologic Modeling System HEC-HMS: Quick Start Guide, US Army Corps of Engineers, Hydrologic Engineering Center, 2013.

[30] R. Meenu, S. Rehana, and P. P. Mujumdar, “Assessment of hydrologic impacts of climate change in Tunga-Bhadra river basin, India with HEC-HMS and SDSM," Hydrological Processes, vol. 27, no. 11, pp. 1572-1589, 2013.

[31] B. Khaniya, S. Wanniarachchi, and U. Rathnayake, "Importance of hydrologic simulation for lids and BMPs design using HEC-HMS: a case demonstration," International Journal of Hydrology, vol. 1, no. 5, pp. 138-146, 2017.

[32] M. E. Alfy, "Assessing the impact of arid area urbanization on flash floods using GIS, remote sensing, and HEC-HMS rainfall-runoff modelling," Hydrology Research, vol. 47, no. 6, pp. pp1142-1160, 2016.

[33] M. M. G. T. De Silva, S. B. Weerakoon, and S. Herath, "Modeling of event and continuous flow hydrographs with HEC-HMS: case study in the Kelani River Basin, Sri Lanka," Journal of Hydrologic Engineering, vol. 19, no. 4, pp. 800-806, 2014.

[34] D. Halwatura and M. M. M. Najim, "Application of the HECHMS model for runoff simulation in a tropical catchment," Environmental Modelling \& Software, vol. 46, pp. 155-162, 2013.
[35] P. M. Jayadeera and N. T. S. Wijesekera, "A diagnostic application of HEC- HMS model to evaluate the potential for water management in the ratnapura watershed of Kalu Ganga Sri Lanka," Engineer: Journal of the Institution of Engineers, Sri Lanka, vol. 52, no. 3, pp. 11-21, 2019.

[36] H. Nandalal and U. Ratnayake, "Event based modeling of a watershed using HEC-HMS," Engineer: Journal of the Institution of Engineers, Sri Lanka, vol. 43, no. 2, pp. 28-37, 2010, https://engineer.sljol.info/articles/10.4038/engineer.v43i2. 6979/galley/5467/download/.

[37] D. S. Sampath, S. B. Weerakoon, and S. Herath, "HEC-HMS model for runoff simulation in a tropical catchment with intra-basin diversions-case study of the Deduru Oya river basin, Sri Lanka," Engineer: Journal of the Institution of Engineers, Sri Lanka, vol. 48, no. 1, pp. 1-9, 2015.

[38] T. T. Vu, L. Li, and K. S. Jun, "Evaluation of multi-satellite precipitation products for streamflow simulations: a case study for the han river basin in the Korean Peninsula, East Asia," Water, vol. 10, no. 5, p. 642, 2018.

[39] W. Ouédraogo, J. Raude, and J. Gathenya, "Continuous modeling of the mkurumudzi river catchment in Kenya using the HEC-HMS conceptual model: calibration, validation, model performance evaluation and sensitivity analysis," Hydrology, vol. 5, no. 3, pp. 44-18, 2018.

[40] D. V. Maidment, V. T. Chow, and L. W. Mays, Applied Hydrology, McGraw-Hill International Editions, Singapore, 1988.

[41] M. Cai, M. Koopialipoor, D. J. Armaghani, and B. Thai Pham, "Evaluating slope deformation of earth dams due to earthquake shaking using MARS and GMDH techniques," Applied Sciences, vol. 10, no. 4, p. 1486, 2020.

[42] M. Koopialipoor, E. Ghaleini, H. Tootoonchi, D. Armaghani, M. Haghighi, and A. Hedayat, "Developing a new intelligent technique to predict overbreak in tunnels using an artificial bee colony-based ANN," Environmental Earth Sciences, vol. 78, no. 5, 2019.

[43] L. Sun, M. Koopialipoor, D. Armaghani, R. Tarinejad, and M. Tahir, "Applying a meta-heuristic algorithm to predict and optimize compressive strength of concrete samples," Engineering with Computers, vol. 37, 2019.

[44] D. Tang, B. Gordan, and M. Koopialipoor, "Seepage analysisin short embankments using developing a metaheuristic method based on governing equations," Applied Sciences, vol. 10, no. 5, p. 1761, 2020.

[45] D. Moriasi, J. Arnold, M. Van Liew, R. Bingner, R. Harmel, and T. Veith, "Model evaluation guidelines for systematic quantification of accuracy in watershed simulations," Transactions of the ASABE, vol. 50, pp. 885-900, 2007.

[46] S. Yoshimoto and G. Amaranath, "Applications of Satellitebased rainfall estimates in flood inundation modeling- A case study in Mundeni Aru River Basin, Sri Lanka," Remote Sensing, vol. 9, no. 10, p. 998, 2017.

[47] A.-u. Rauf and A. Ghumman, "Impact assessment of rainfallrunoff simulations on the flow duration curve of the upper indus river-A comparison of data-driven and hydrologic models," Water, vol. 10, no. 7, p. 876, 2018.

[48] C. Young and W. Liu, "Prediction and modelling of rainfall-runoff during typhoon events using a physically-based and artificial neural network hybrid model," Hydrological Sciences Journal, vol. 60, no. 12, pp. 2102-2116, 2015.

[49] S. N. Loyeh and M. R. Jamnani, "Comparison of different rainfall-runoff models performance: a case study of Liqvan catchment, Iran," European Water, vol. 57, pp. 315-322, 2017. 
[50] Y. Tramblay, V. Thiemig, A. Dezetter, and L. Hanich, "Evaluation of satellite-based rainfall products for hydrological modelling in Morocco," Hydrological Sciences Journal, vol. 61, no. 14, pp. 2509-2519, 2016.

[51] C. Perrin, C. Michel, and V. Andréassian, "Improvement of a parsimonious model for streamflow simulation," Journal of Hydrology, vol. 279, no. 1-4, pp. 275-289, 2003.

[52] P. Gilewski and M. Nawalany, "Inter-comparison of raingauge, radar, and satellite (IMERG GPM) precipitation estimates performance for rainfall-runoff modeling in a mountainous catchment in Poland," Water, vol. 10, no. 11, Article ID 1665, 2018.

[53] T. M. Sharannya, N. Al-Ansari, S. Deb Barma, and A. Mahesha, "Evaluation of satellite precipitation products in simulating streamflow in a humid tropical catchment of India using a semi-distributed hydrological model," Water, vol. 12, no. 9, pp. 2400-2422, 2020. 